\title{
Inmunohistoquímica de los cambios degenerativos del sistema nervioso central en paraparesias espásticas asociadas al virus linfotrópico humano T tipo I (HTLV-I)
}

\author{
Luis Cartier $\mathbf{R}$, Carmen Vergara $\mathbf{R}^{\mathbf{a}}$,
} María Antonieta Valenzuela $\mathrm{P}^{\mathrm{b}}$.

\section{Immunohistochemistry of degenerative changes in the central nervous system in spastic paraparesis associated to human T lymphotropic virus type I (HTLV-I)}

Background: Human T lymphotropic virus type I is associated with tropical spastic paraparesis, that is a chronic and progressive disease which damages specially the cortiespinal tracts. The pathogenesis of this degenerative process remains unknown. Aim: To identify histopathological aspects that could suggest a pathogenic hypothesis we studied immunohistochemical features in spinal cords obtained from patients that died due to progressive spastic paraparesis. Patients and Methods: Five males and five females, who died between 1990 and 2000, with a mean age of 52 years and mean disease duration of 8.6, were studied. All had a complete clinical and virological diagnosis. Samples were obtained from the frontal motor cortex and spinal cord (cervical, dorsal and lumbar segments), were fixed in formol (10\%), included in paraffin, and stained with Haematoxylin and Luxol-fast-blue. Immunohistochemical study was made with anti-neurofilament antibodies 1:100 (MO762, DAKO), anti-APP 1:20 (Rabbit Pre Amyloid protein 51-2700 ZYMED), antitau 1:100 (A0024 DAKO) and anti-ubiquitine 1:50 (NCL UBIQm Novocastra). Results: All cases had demyelinization and axonal loss in the cortico-spinal tracts; distal and segmental demyelinization of Goll tract; axonal thickening, amyloid precursor protein deposits in the white matter; tau protein aggregation in the spinal cord oligodendrocytes; axonal ubiquitination of sensitive and motor tracts, and subcortical white matter. Neuronal injury was absent. Conclusions: The systematic damage of motor and sensitive tracts of the spinal-cord and the absence of neuronal damage, defines a degenerative process limited to axons. This central axonopathie could be caused by a disturbance of axoplasmic transport (Rev Méd Chile 2007; 135: 1139-46).

(Key words: Axonal injury, diffuse; Human T-lymphotropic virus; Paraparesis, tropical spastic)

Recibido el 2 de agosto, 2006. Aceptado el 12 de marzo, 2007.

Este trabajo ha sido financiado con el proyecto FONDECYT \# 1050784.

Departamento de Ciencias Neurológicas, Facultad de Medicina, Universidad de Chile.

aTecnólogo Médico

${ }^{\mathrm{b}} \mathrm{Químico}$ Farmacéutico

Correspondencia a: Luis Cartier R. Luis Thayer-Ojeda 717.

Santiago, Chile. E mail: lcartier@ med.uchile.cl 
T a paraparesia espástica asociada a HTLV-I es una enfermedad que compromete la vía motora central. Se expresa por trastornos de la marcha, originados en espasticidad y disminución de la potencia muscular en las extremidades inferiores.

Es lentamente progresiva, sin remisiones y clínicamente define un síndrome piramidal bilateral, hiperreflexia osteotendínea, signo de Babinski y vejiga neurogénica ${ }^{1}$.

El 86,3\% presenta compromiso sensitivo subclínico de los cordones posteriores, definido con potenciales evocados somatosensoriales ${ }^{2}$. La resonancia magnética de la médula espinal muestra atrofia en los segmentos dorsales ${ }^{3}$. La identificación histopatológica está basada en la desmielinización y pérdida bilateral de axones del haz corticoespinal, palidez mielínica en los segmentos cervicales del haz de Goll y manguitos linfocitarios perivasculares, en la mitad de los casos ${ }^{4}$.

La paraparesia espástica asociada a HTLV-I, muestra gran semejanza clínica e histopatológica con algunas paraparesias espásticas hereditarias ${ }^{5}$, cuya patogenia ha sido atribuida a disfunciones del transporte axoplásmico. En la paraparesia hereditaria autosómica dominante SPG4, originada por mutaciones de la espastina, se altera la dinámica de los microtúbulos ${ }^{6,7}$. La forma SPG10 muestra perturbaciones en las proteínas transportadoras (kinesinas) ${ }^{8}$. Por mutaciones de la paraplejina, la forma autosómica recesiva SPG7 induce alteraciones mitocondriales ${ }^{9}$. La falla del transporte axónico de cualquier origen, produce alteraciones en la reposición de organelos y proteínas estructurales, desarticulando la morfogénesis, funcionamiento y sobrevida del sistema neuroaxonal. La detención del flujo axoplásmico se identifica histológicamente por la acumulación de proteína precursora del amiloide (APP) ${ }^{10}$, y por la formación de dilataciones localizadas (torpedos) y engrosamientos axonales ${ }^{11}$. Estos cambios degenerativos producidos por la detención del transporte se diferencian substancialmente de las modificaciones estructurales ocasionadas por procesos inflamatorios o vasculares, que suelen inducir una degeneración walleriana. La degeneración walleriana es una forma de apoptosis axonal, originada por el ingreso programado de calcio al axón ${ }^{12}$, que produce su fragmentación total en 48 $\mathrm{h}^{13}$. Sin embargo, ratas Wlds (degeneración walleriana lenta) que tienen un bloqueo natural de los canales de calcio, muestran una latencia de dos a tres semanas antes de iniciar la degeneración walleriana retardada. Esta forma retardada afecta gradualmente de proximal a distal. Se interpreta como el déficit de proteínas estructurales, consecutivo a la solución de continuidad del axón ${ }^{13}$. Aunque todos los axones y dendritas sintetizan proteínas ${ }^{14}$, fallas prolongadas del flujo axoplásmico inducen cambios tróficos, funcionales y degenerativos en el axón. Especialmente vulnerables son los haces corticoespinales nacidos de las motoneuronas de la corteza frontal, cuyos axones suelen superar el metro de longitud y tienen un volumen mil veces superior al de la neurona ${ }^{15}$. Transporte axoplásmico deficitario, disfunciones mitocondriales, 0 aumento intraxonal de calcio, son factores que indistintamente ocasionan degeneración axonal ${ }^{16}$.

En una serie de 10 pacientes portadores de una paraparesia espástica HTLV-I, se intenta definir, con inmunohistoquímica, la característica de los cambios degenerativos de los largos axones espinales, para intentar develar su patogenia.

\section{PACIENTES Y MÉTODO}

Diez pacientes con paraparesia espástica progresiva asociada a HTLV-I, seguidos clínicamente en el Hospital del Salvador (Departamento de Ciencias Neurológicas, Escuela de Medicina, Universidad de Chile), fallecidos entre 1990 y 2000, fueron analizados desde el estudio inmunohistoquímico de su sistema nervioso central (SNC). Serológicamente definidos para HTLV-I y PCR confirmatorio, cuyo estudio neurológico, de líquido cefalorraquídeo, hematológico, inmunológico, electrofisiológico y radiológico, permitieron establecer su diagnóstico en vida. Serie compuesta por cinco mujeres y cinco hombres con una edad promedio de 51,7 años y una media de enfermedad de 8,6 años. En la etapa previa al estudio neuropatológico, cuatro de los enfermos tenían marcha independiente, tres caminaban con apoyo y sólo tres no tenían marcha (Tabla 1). Se estudiaron muestras de corteza y substancia blanca frontal, mesencéfalo, protuberancia, bulbo raquídeo y médula (cervical, dorsal, lumbar), de material fijado en formol al $10 \%$ e incluido en parafina. Todos los cortes fueron teñidos con: hematoxilina-eosina, 
Tabla 1. D atos biográficos y hallazgos histológicos

\begin{tabular}{|c|c|c|c|c|c|c|c|c|c|c|}
\hline Caso & $\begin{array}{l}\text { Edad/ } \\
\text { Sexo }\end{array}$ & $\begin{array}{l}\text { Evol } \\
\text { años }\end{array}$ & Marcha & $\begin{array}{l}\text { Pérdida de } \\
\text { mielina }\end{array}$ & $\begin{array}{l}\text { Pérdida de } \\
\text { axones }\end{array}$ & APP & Tau & Ubiquitina & Linfocitos & $\begin{array}{l}\text { Segmento } \\
\text { del SNC }\end{array}$ \\
\hline 1 & $57 / \mathrm{F}$ & 6 & $\begin{array}{l}\text { Marcha } \\
\text { independiente }\end{array}$ & $\begin{array}{l}++P \\
+G\end{array}$ & $\begin{array}{l}+ \\
+ \\
-\end{array}$ & $\begin{array}{l}+ \\
++ \\
-\end{array}$ & $\begin{array}{l}++ \\
+ \\
+\end{array}$ & $\begin{array}{l}+ \\
+ \\
+\end{array}$ & $\begin{array}{l}- \\
-\end{array}$ & $\begin{array}{l}\text { Dorsolumbar } \\
\text { Cervical } \\
\text { Cerebral }\end{array}$ \\
\hline 2 & $51 / F$ & 4 & $\begin{array}{l}\text { Marcha } \\
\text { apoyo }\end{array}$ & $\begin{array}{l}++P \\
++P G \\
+\end{array}$ & $\begin{array}{l}\text { H+T } \\
++ \\
-\end{array}$ & $\begin{array}{l}+ \\
+ \\
-\end{array}$ & $\begin{array}{l}H \\
+ \\
-\end{array}$ & $\begin{array}{l}++ \\
+ \\
+\end{array}$ & $\begin{array}{l}++ \\
++ \\
+\end{array}$ & $\begin{array}{l}\text { Dorsolumbar } \\
\text { Cervical } \\
\text { Cerebral }\end{array}$ \\
\hline 3 & $54 / \mathrm{M}$ & 6 & $\begin{array}{l}\text { Sin } \\
\text { marcha }\end{array}$ & $\begin{array}{l}+++P \\
++P G \\
-\end{array}$ & $\begin{array}{l}++\mathrm{T} \\
++ \\
-\end{array}$ & $\begin{array}{l}+ \\
+ \\
-\end{array}$ & $\begin{array}{l}+ \\
+ \\
-\end{array}$ & $\begin{array}{l}+ \\
+ \\
+\end{array}$ & $\begin{array}{l}++ \\
++ \\
-\end{array}$ & $\begin{array}{l}\text { Dorsolumbar } \\
\text { Cervical } \\
\text { Cerebral }\end{array}$ \\
\hline 4 & $57 / \mathrm{F}$ & 8 & $\begin{array}{l}\text { Marcha } \\
\text { independiente }\end{array}$ & $\begin{array}{l}++P \\
++G\end{array}$ & $\begin{array}{l}++\mathrm{T} \\
+ \\
-\end{array}$ & $\begin{array}{l}++ \\
++ \\
+\end{array}$ & $\begin{array}{l}++ \\
+ \\
+\end{array}$ & $\begin{array}{l}++ \\
+ \\
+\end{array}$ & $\begin{array}{l}- \\
-\end{array}$ & $\begin{array}{l}\text { Dorsolumbar } \\
\text { Cervical } \\
\text { Cerebral }\end{array}$ \\
\hline 5 & $35 / M$ & 4 & $\begin{array}{l}\text { Marcha } \\
\text { apoyo }\end{array}$ & $\begin{array}{l}\text { ++ P } \\
++\mathrm{GP} \\
-\end{array}$ & $\begin{array}{l}+++\mathrm{T} \\
++\end{array}$ & $\begin{array}{l}++ \\
+ \\
-\end{array}$ & $\begin{array}{l}+ \\
+ \\
-\end{array}$ & $\begin{array}{l}+ \\
+ \\
-\end{array}$ & $\begin{array}{l}++ \\
++\end{array}$ & $\begin{array}{l}\text { Dorsolumbar } \\
\text { Cervical } \\
\text { Cerebral }\end{array}$ \\
\hline 6 & $44 / \mathrm{M}$ & 5 & $\begin{array}{l}\text { Sin } \\
\text { marcha }\end{array}$ & $\begin{array}{l}++P \\
++P \\
+\end{array}$ & $\begin{array}{l}++ \\
+ \\
-\end{array}$ & $\begin{array}{l}+ \\
+ \\
+\end{array}$ & $\begin{array}{l}H \\
+ \\
-\end{array}$ & $\begin{array}{l}+ \\
+ \\
+\end{array}$ & $\begin{array}{l}- \\
- \\
-\end{array}$ & $\begin{array}{l}\text { Dorsolumbar } \\
\text { Cervical } \\
\text { Cerebral }\end{array}$ \\
\hline 7 & $71 / \mathrm{M}$ & 20 & $\begin{array}{l}\text { Marcha } \\
\text { independiente }\end{array}$ & $\begin{array}{l}+\mathrm{P} \\
+\mathrm{P} \\
-\end{array}$ & $\begin{array}{l}+\mathrm{T} \\
+\end{array}$ & $\begin{array}{l}++ \\
+ \\
-\end{array}$ & $\begin{array}{l}+ \\
+ \\
-\end{array}$ & $\begin{array}{l}++ \\
+ \\
+\end{array}$ & - & $\begin{array}{l}\text { Dorsolumbar } \\
\text { Cervical } \\
\text { Cerebral }\end{array}$ \\
\hline 8 & $40 / \mathrm{M}$ & 17 & $\begin{array}{l}\text { Sin } \\
\text { marcha }\end{array}$ & $\begin{array}{l}++\mathrm{P} \\
++\mathrm{GP} \\
+\end{array}$ & $\begin{array}{l}\text { H+T } \\
H\end{array}$ & $\begin{array}{l}+ \\
+ \\
-\end{array}$ & $\begin{array}{l}++ \\
+ \\
+\end{array}$ & $\begin{array}{l}++ \\
+ \\
+\end{array}$ & $\begin{array}{l}+ \\
+ \\
+\end{array}$ & $\begin{array}{l}\text { Dorsolumbar } \\
\text { Cervical } \\
\text { Cerebral }\end{array}$ \\
\hline 9 & $48 / \mathrm{F}$ & 6 & $\begin{array}{l}\text { Marcha } \\
\text { independiente }\end{array}$ & $\begin{array}{l}++\mathrm{P} \\
++\mathrm{GP} \\
-\end{array}$ & $\begin{array}{l}++\mathrm{T} \\
++ \\
-\end{array}$ & $\begin{array}{l}++ \\
+ \\
-\end{array}$ & $\begin{array}{l}++ \\
+ \\
-\end{array}$ & $\begin{array}{l}++ \\
+ \\
+\end{array}$ & $\begin{array}{l}++ \\
+++ \\
+\end{array}$ & $\begin{array}{l}\text { Dorsolumbar } \\
\text { Cervical } \\
\text { Cerebral }\end{array}$ \\
\hline 10 & $69 / \mathrm{F}$ & 10 & $\begin{array}{l}\text { Marcha } \\
\text { apoyo }\end{array}$ & $\begin{array}{l}+P \\
+P \\
-\end{array}$ & $\begin{array}{l}+ \\
+ \\
-\end{array}$ & $\begin{array}{l}+ \\
+ \\
-\end{array}$ & $\begin{array}{l}+ \\
+ \\
-\end{array}$ & $\begin{array}{l}++ \\
+ \\
-\end{array}$ & - & $\begin{array}{l}\text { Dorsolumbar } \\
\text { Cervical } \\
\text { Cerebral }\end{array}$ \\
\hline
\end{tabular}

G: haz de Goll. P: haz piramidal. T: torpedo axonal. Evol = evolución.

luxol-fast-blue, Gomori y Nissl. La inmunohistoquímica incluyó: anti-tau (A0024 DAKO) 1:100; antineurofilamentos (Neurofilaments protein MO762 DAKO) 1:100; anti-APP (Rabbit Pre Amyloid Protein 51-2700ZYMED) 1:20; anti-GFAP (Z0334 DAKO) 1:1000; anti-MAB 328 oligodendrocytes; anti-B Amyloid 1:100 (Novo Castra, New Castle, Reino Unido); anti-ubiquitina (NCL UBIQm, Novo Castra, New Castle, Reino Unido) 1:50. Los cortes fueron desparafinados y rehidratados en alcohol hasta el agua. La inmunorreactividad fue recuperada con diferentes métodos. Para APP, con un pretratamiento en citrato de sodio a $\mathrm{pH} \mathrm{6,} \mathrm{por}$ diez minutos en microonda, para lograr la recuperación antigénica. Para amiloide, con ácido fórmico al 96\% durante cinco minutos. Para el resto de los anticuerpos se realizó con target retrieval (DAKO) 1.10. Como se usó inmunoperoxidasas, fue necesario el bloqueo previo de las peroxidasas endógenas, con peróxido de hidrógeno al 0,3\% en metanol. Se lavó en buffer 0,05 M tris HCL En el revelado se ocupó el kit LSAB peroxidasa (DAKO). Para visualizar la reacción fue utilizado el cromógeno DAB. En todos los experimentos se usaron 
controles negativos, con omisión de anticuerpo primario. Se estimaron cuantitativamente los cambios histológicos, definiendo en 3 cruces el daño máximo (Tabla 1).

\section{Resultados}

Aspecto macroscópico de la médula espinal y tronco cerebral. En ocho de diez casos se observó una disminución del diámetro en los segmentos dorsales de la médula espinal. Se apreció un estrechamiento de los cordones laterales, que lograban modificar la forma habitualmente redondeada $\mathrm{u}$ oval de la médula, por una apariencia triangular. Macroscópicamente los cordones posteriores y la substancia gris no mostraron cambios, tampoco se observaron alteraciones estructurales en el bulbo raquídeo, protuberancia 0 mesencéfalo (Figura 1).

Histología convencional. Se encontró desmielinización y pérdida de gran número de axones en los cordones laterales (haz piramidal), tanto en los segmentos lumbares como dorsales y, en menor grado, en los segmentos cervicales. El haz de Goll mostró desmielinización, limitada a los segmentos distales de los axones, a nivel cervical (Figuras $2 \mathrm{~A}$ y B). Se observó engrosamiento meníngeo y de la adventicia de los vasos y se comprobó la conservación estructural de las neuronas. Presencia de linfocitos perivasculares se vio en la mitad de los casos (Figura $2 \mathrm{C}$ ); estos manguitos linfocitarios afectaban vasos de las astas anteriores, cordones laterales y meninges en la médula espinal, también se encontraron en el bulbo raquídeo, protuberancia o estructuras cerebrales (tálamo). Una notable afluencia linfocitaria a la médula, se vio en los casos dos y nueve, sin producir mayores cambios estructurales.

\section{Inmunohistoquímica}

Anti-neurofilamentos: Con esta técnica se definió pérdida de axones, relevante en los haces corticoespinales. En los casos dos, cinco, seis y ocho, la pérdida llegó a ser muy completa, especialmente en los segmentos lumbares y dorsales. En los otros casos, se apreció una pérdida sólo parcial y selectiva de axones piramidales. También se notó presencia de axones dilatados y de torpedos, especialmente en la proximidad de las motoneuronas y en los sectores en que el haz piramidal ingresa en la substancia gris (Figuras $3 \mathrm{~A}$ y B). No se encontró una clara pérdida de axones en el haz de Goll, distalmente desmielinizado en los segmentos cervicales, aunque se observaron dilataciones axonales. No se apreciaron cambios significativos en las neuronas.

Anti-APP: En todos los casos se vieron depósitos de APP, dispuestos en forma aleatoria en la substancia blanca de la médula espinal. En cortes transversales de la médula, tomaban un aspecto redondeado-estrellado, de entre 30 y 150 micrones de diámetro, apareciendo más frecuentemente en los segmentos dorsales y cervicales, y en los cordones posteriores y laterales. Los depósitos de APP tendían a difundir al parénquima circundante desde axones dilatados rellenos de material intensamente teñido con anti-APP (Figuras $3 \mathrm{C}$ y D). Estos depósitos eran menores en casos de evolución prolongada o mayor pérdida de axones. En cuatro pacientes se encontraron depósitos de APP también en la substancia blanca frontal.
Figura 1. Médula dorsal (T6) de apariencia triangular. La pérdida de axones y mielina del cordón lateral, contrasta con la conservación del cordón posterior. LFB X 4 (Caso 3).

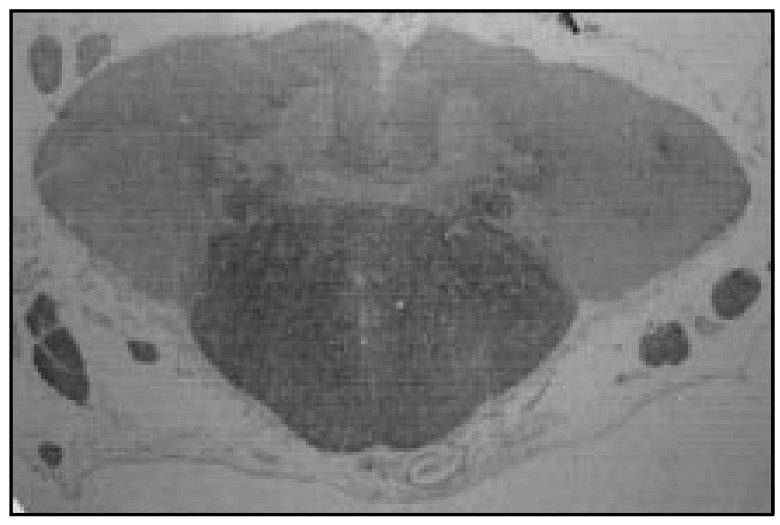




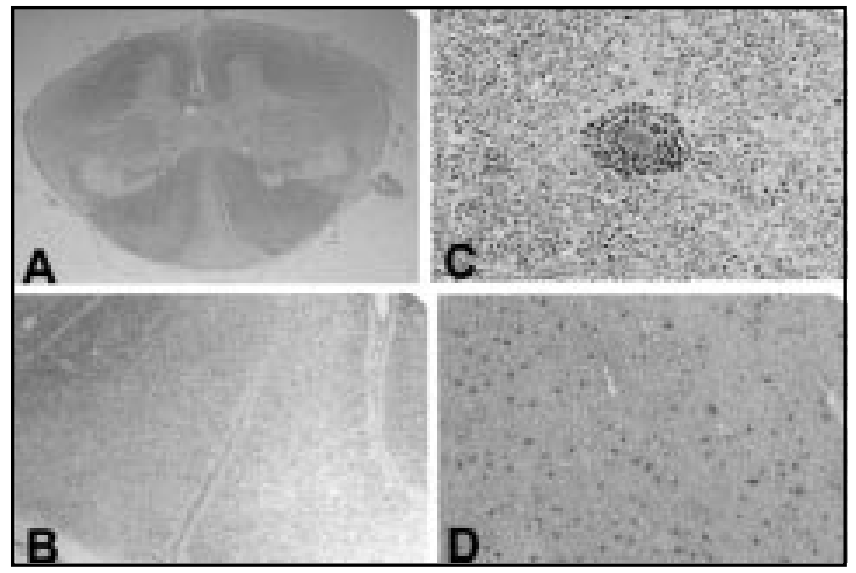

Figura 2 A y B. Médula cervical (C2). Pérdida selectiva de mielina en algunos axones del haz de Goll. A. LFB X 4. / B. LFB X 100. (Caso 5). C. Manguito linfocitario perivascular característico, que no altera el parénquima circundante. HE + LFB X 200. (Caso 9). D. Reacción glíal, cordón lateral. Anti-GFAP X 100 (Caso 2).

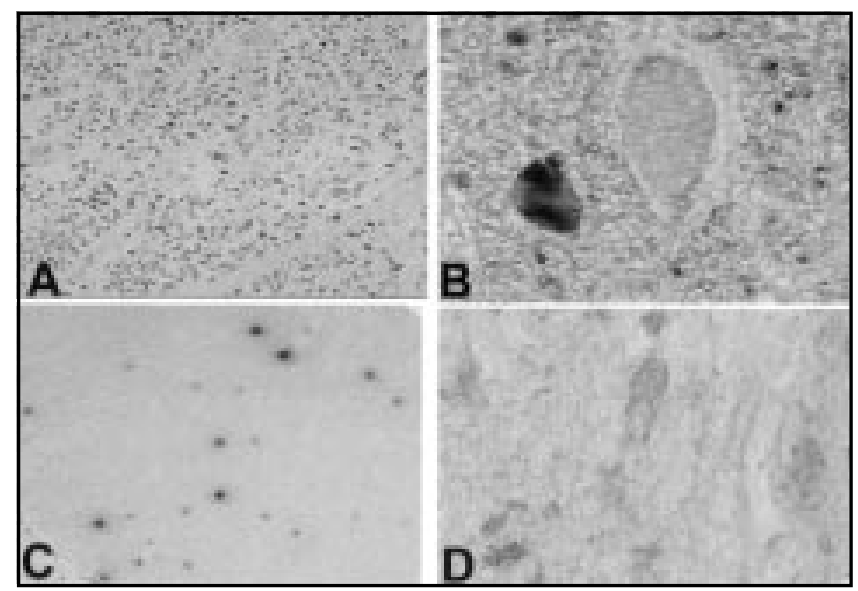

Figura 3 A. Médula dorsal (T8) pérdida y engrosamiento selectivo de axones del cordón lateral. Antineurofilamentos $\mathrm{x}$ 100. (Caso 7). B. Médula lumbar (L2) Torpedos axonales, área paraneuronal. Antineurofilamentos x 200. (Caso 6). C y D. Médula dorsal, cordón lateral, depósitos de proteína precursora del amiloide (APP) en C -Anti-APP X 100. D. Dilataciones axonales teñidas con Anti-APP X 200 (Caso 4).

Anti-tau: En la médula espinal se encontró acumulación de proteína tau en oligodendrocitos ubicados en cordones laterales, posteriores y en aquellos próximos a las motoneuronas. Algunos oligodendrocitos mostraban su citoplasma distendido por depósitos de tau. También, se observó agregación de tau en axones engrosados. Los casos uno y siete mostraron oligodendrocitos con tau en áreas có rtico-subcorticales frontales. No encontramos agregación de tau en neuronas, corticales o medulares (Figuras 4 A y B).

Anti-ubiquitina: La ubiquitina se expresó en forma de pequeñas perlas que seguían trayectos axonales, con una disposición arrosariada. Frecuentemente, se visualizó la ubiquitina de axones aún mielinizados, en axones dilatados de la médula espinal y en la substancia blanca frontal (Figuras $4 \mathrm{C}$ y D). También se vio ubiquitinación de algunos axones de las raíces posteriores de la médula.

Anti-GFAP: La glía estaba aumentada tanto en la substancia blanca como gris. La gliosis fue más notable en la substancia gris paraneuronal y áreas con pérdida axonal (Figura $2 \mathrm{D}$ ).

Anti-B amiloide: No se encontraron depósitos de beta amiloide.

En la Tabla 1 se señala, en cada caso, la intensidad de estos cambios inmunohistoquímicos.

\section{DisCUSIÓN}

El estudio inmunohistoquímico de la médula espinal y corteza motora del cerebro, en diez pacientes que desarrollaron una paraparesia espástica progresiva asociada a HTLV-I, mostró: depósitos de APP en la substancia blanca, engrosamientos y pérdida de axones del haz corticoespinal, desmielinización distal del haz de Goll, agregación de proteína tau en los oligodendrocitos de la médula espinal, ubiquitinización de axones y ausencia de lesiones en las neuronas. Estas alteraciones sistematizadas de la sustancia blanca definen una axonopatía central. El daño secuencial de los axones motores más largos es clínicamente concordante con la debilidad progresiva de los músculos inervados por ellos ${ }^{17} \mathrm{y}$ patogénicamente sugerente de una falla en el transporte axonal.

Las alteraciones del flujo axoplásmico se expresan histológicamente por la presencia de cúmulos de APP, como se apreció en este estudio 
inmunohistoquímico y anteriormente, por Umehara et $\mathrm{al}^{18}$. La APP es transportada en forma de vesículas, mediante transporte rápido anterógrado, por la kinesina 1. Las kinesinas transportan numerosas proteínas de manera específica, porque disponen de adaptadores o selectores, que permiten dirigirlas adecuadamente al sitio de acción de los cargos. La detención del transporte produce acumulación de APP en los sectores prenodales de los axones (nódulos de Ranvier) ${ }^{11}$. En las paraparesias HTLV-I, los depósitos de APP en la médula espinal y también en áreas subcorticales, confirmarían las alteraciones del transporte axonal. El compromiso de axones de la substancia blanca cerebrales, hace compresible el daño cognitivo observado en algunos pacientes ${ }^{3,4}$. De igual manera, la presencia de APP en el cerebro de las encefalopatías por HIV, sugiere alteración del transporte axonal ${ }^{19}$. Así como los depósitos de APP que bordean las placas en la esclerosis múltiple, son atribuibles a bloqueos en las áreas lesionadas $^{20}$. La presencia de depósitos de APP, siempre definen alteraciones del transporte axoplásmico rápido ${ }^{10}$.

Tau, en base al grado de fosforilación y a las isoformas específicas de cada neurona o axón, interactúa con los neurotúbulos, en la regulación del transporte axonal ${ }^{21}$. En esta serie de paraparesias, se observó agregación de tau en los oligodendrocitos de la médula espinal, y en axones engrosados, que sugieren cambios funcionales, tal vez específico para algún isómero de tau. La agregación intracelular de tau en neuronas o glía, suele liderar procesos degenerativos del SNC, como es la acumulación de tau hiperfosforilada intraneuronal en la enfermedad de Alzheimer ${ }^{21}$. La disfunción de tau puede ser causa de alteraciones del transporte axoplásmico y su acumulación sinónimo de enfermedad degenerativa ${ }^{22}$.

En base a la observación histopatológica, surge la idea de un daño axonal primario, que ha hecho acuñar el concepto de degeneración axomielínica, para este proceso vinculado al HTLV-I. Hemos querido significar que, siendo los axones los enfermos, la desmielinización es un epifenómeno, aunque aparente ser el comienzo de la enfermedad $^{4}$. En estos casos, la causa de la desmielinización es la desregulación entre axones

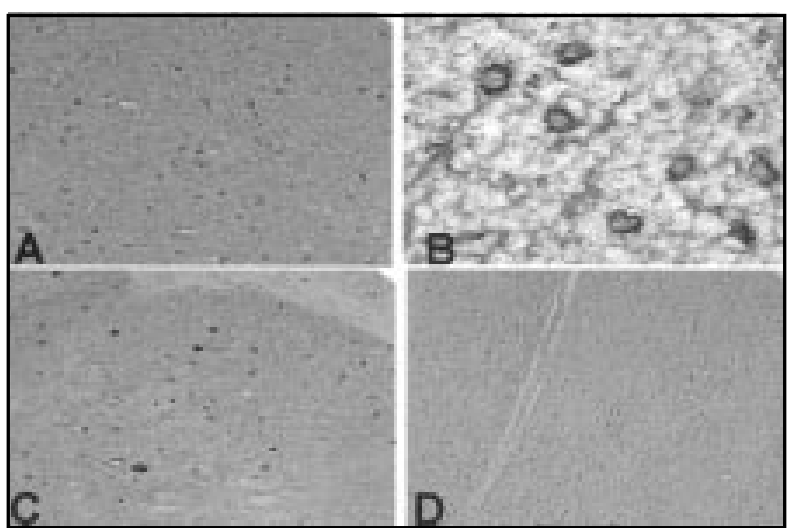

Figura 4 A y B. Médula cervical (C5) Oligodendrocitos que expresan proteína tau en el citoplasma en A Anti tau x 100. B. Anti-tau x 300. (Caso 8) C. Médula dorsal cordón lateral, axones que expresan ubiquitina. Antiubiquitina $\mathrm{x}$ 100. D. Corteza motora, substancia blanca subcortical. Expresión de ubiquitina en trayectos axonales. Antiubiquitina x 100 (Caso 9).

y oligodendrocitos (mielina), que tiene su origen en alteraciones del transporte axonal. Un buen ejemplo es lo observado en el haz de Goll de esta serie de pacientes, donde la desmielinización es sólo segmentaria y distal (cervical), sin pérdida aparente de axones.

En las paraparesias espásticas, la presencia de linfocitos perivasculares es concebida como la expresión de un fenómeno inflamatorio ${ }^{23}$. Sin embargo, en esta enfermedad la presencia de linfocitos activados $^{24}$, en distintos sectores del parénquima nervioso, generalmente lejos de las áreas dañadas, pondría en duda dicha interpretación. En las paraparesias HTLV-I estas «inforragias» no parecen afectar las estructuras parenquimatosas y sólo tiene un carácter presencial, como sucede en algunos linfomas. Pareciendo ser el resultado del aumento en la adhesividad de los linfocitos activados, que el de un propósito inflamatorio específico. No debemos olvidar que $10 \%$ de estos pacientes se asocian a linfoma $\mathrm{T}^{25}$ y que más de $60 \%$ de ellos, tiene aumento de CD4 y linfocitos leucemoides circulantes ${ }^{26}$. Por ello, la forma en que estos linfocitos se disponen, parece quitar significado a la inflamación y los hallazgos descritos refuerzan la idea degenerativa del proceso.

Los linfocitos CD4 infectados, presentes en el líquido cefalorraquídeo de las paraparesias HTLVI, secretan permanentemente proteína Tax del virus, originada en el gen tax incorporado al 
genoma linfocitario ${ }^{27}$. Tax es una proteína activadora, cuyo contacto con diferentes receptores de la matriz extracelular, facilita su intervención en sistemas transcripcionales como: modos de fosforilación, acetilación y ubiquitinación de estructuras específicas. Debe consignarse, a modo de ejemplo, que el complejo establecido por Tax con la kinasa 4, aumenta la capacidad de fosforilación e inhibe la desfosforilación ${ }^{28}$. Experimentalmente, también se ha demostrado que Tax interactúa con los neurofilamentos ${ }^{29}$. Las múltiples posibilidades interventoras que posee Tax, la califican para desencadenar cambios que culminen en la degeneración axomielínica, que identifica la paraparesia espástica ligada a HTLV-I.

Aunque Tax es una proteína extraña, no suele encontrarse acoplada al proteosoma para su destrucción, sino que se halla monoubiquitinizada, una forma que no parece tener un propósito proteolítico final, como ocurre con otras proteínas, La monoubiquitinación buscaría la regulación

\section{REFERENCIAS}

1. Cartier L, Mora C, Araya F, Castilo JL, Verdugo R, MileR MA AT el. HTLV-I positive spastic paraparesis in a temperate zone. Lancet 1989; 2: 556-7.

2. CastiLo JL, Cea JG, Verdugo RJ, Cartier L Sensory dysfunction in HTLV-I associated myelopathy/tropical spastic paraparesis. Eur Neurol 1999; 42: 17-22.

3. Cervila J, Cartier L, García L Resonancia magnética de médula espinal y cerebro en el correlato clínico de la paraparesia espástica progresiva que se asocia al virus humano linfotrópico tipo-I (HTLV-I). Rev Méd Chile 2006; 134: 1010-8.

4. Cartier L, Cea JG, Vergara C, Araya F, Born P. Clinical and neuropathological study of six patients with spastic paraparesis associated with HTLV-I: An axomyelinic degeneration of the central nervous systems. J Neuropath Exp Neurol 1997; 56: 403-13.

5. Behan W, Maia $H$. Strümpell's familiar spastic paraplegia: Genetic and neuropathology. J Neurol Neurosurg Psychiatry 1974; 37: 8-20.

6. Errico A, Ballabio A, Rugari EI. Spastin, the protein mutated in autosomal dominant hereditary, spastic paraplegia, is involved in microtubule dynamics. Human Mol Genet 2002; 11: 153-63. de Tax, con el objeto de limitar o impedir su intervención en factores transcripcionales. Tax, se monoubiquitiniza dentro de los linfocitos y es secretado entre $54 \%$ y $72 \%$ en esas condiciones ${ }^{30}$. En este estudio, la presencia de ubiquitina intraxonal que incluye axones dilatados que parecen estar dañados y en etapa proteolítica, muestra también axones ubiquitinizados que conservan la mielina, hecho que estaría sugiriendo otra interpretación para su presencia. Si la ubiquitina, como se ha propuesto, tiene una acción estabilizadora de Tax, es posible que ella a nivel axonal juegue algún papel no establecido. Como ocurre con la presencia intraxonal de ubiquitina en axones de apariencia normal en otras patologías, como en la esclerosis múltiple con axones que están distantes de las placas ${ }^{25}$.

La paraparesia espástica HTLV-I patogénicamente sería una axonopatía central, producto de alteraciones en el transporte axoplásmico que originaría el virus.

7. Mc Dermott CH, Grierson AJ, Wood JD, Bingley M, WhaRTon SB, BushBY K, Shaw OP. Hereditary spastic paraparesis disnupted intracellular transport associated with spastin mutation. Ann Neurol 2003; 54: 758-9.

8. Reid E, Kloos M, Ashiey-Koch A, Hughes L, Bevan S, SVENSON IK ET AL. A kinesin heavy chain (KIF5A) mutation in Hereditary Spastic Paraplegia (SPG10). Am J Hum Genet 2002; 71: 1189-94.

9. Ferrerinha F, Quattrini A, Pirozzi M, Valsecchi V, Dina G, Broccoli V et al. Axonal degeneration in paraplegin-deficient mice is associated with abnormal mitochondria and impairment of axonal transport. J Clin Invest 2004; 113: 231-42.

10. Lazarov O, Morfini GA, Lee EB, Farah MB, Szodoral A, Deboer SR et al. Axonal transport, amyloid precursor protein, kinesin-1, and the processing apparatus: Revisited. J Neuroscience 2005; 25: 2386-95.

11. HiRoKaWA N, TAKEMURA R. Molecular motors and mechanisms of directional transport in neurons. Nature Reviews/Neuroscience 2005; 6: 201-14.

12. RafF MC, Whitmore AV, FinN JT. Axonal selfdestruction and neurodegeneration. Science 2002; 296: 868-71.

13. Beirowski B, Adalbert R, Wagner $D$, Grumme $D S$, Addicks K, Ribchester RR, Coleman MP. The progre- 
ssive nature of Wallerian degeneration in wildtype and slow Wallerian degeneration (Wlds) nerves. BMC Neuroscience 2005; 6: 1-27.

14. Giuditta A, Kaplan BB, Van Minnen J, Alvarez J, Koening E. Axonal a presinaptic protein sintesis: New insights in to the biology of the neuron. Trends Neurosci 2002; 25: 400-4.

15. GoLDSTEIN LSB. Kinesin molecular motors: transport pathways, receptors, and human disease. Proc Nat Acad Sci USA 2001; 98: 6999-7003.

16. Coleman M. Axon degeneration mechanisms: commonality amid diversity. Nature Rev Neuroscience 2005; 6: 889-98.

17. Cartier L, Araya F, Castilo JL, Gormaz A, tajima N. Progressive spastic paraparesis associated with human $\mathrm{T}$ cell leukemia virus type I (HTLV-I). Intern Med 1992; 31: 1257-61.

18. Umehara $F$, Abe M, Koreeda $Y$, Izumo S, Osame M. Axonal damage revealed by accumulation of beta-amyloid precursor protein in HTLV-I associated myelopathy. J Neurol Sci 2000; 176: 95-101.

19. Green DA, Maslah E, Vinters HV, Beizai P, Moore DJ, AснIм CL. Brain deposition of beta-amyloid is a common pathologic feature in HIV patients. AIDS 2005; 19: 407-11.

20. Giordana MT, Richiardi $\mathrm{P}$, Trevisan E, Boghi A, PALMUCCI L Abnormal ubiquitination of axons in normally myelinated white matter in multiple sclerosis brain. Neuropath Appl Neurobiol 2002; 28: 35-41.

21. Sergeant N, Delacourte A, BuÉe L. Tau protein as a differential biomarker of tauopathies. Acta Biochem Biophys 2005; 1739: 179-97.

22. Stamer K, Vogel R, Thies E, Mandelkow E, MandeLKow M. Tau blocks traffic of organelles, neurofilaments, and APP vesicles in neurons and enhances oxidative stress. J Cell Biol 2002; 156:1051-63.

23. IWASAKI Y. Pathology of chronic myelopathy associated with HTLV-I infection (HAM/TSP). J Neurol Sci 1990; 30: 103-23.

24. Umehara F, Izumo S, RonquiLO AT, Matsumuro $K$, Sato E, Osame M. Cytokine expression in the spinal cord lesions in HTLV-I associated myelopathy. J Neuropath Exp Neurol 1994; 53: 72-7.

25. Cabrera ME, Labra S, Catovsky D, Ford AM, Colman SM, ReAves MF. HTLV-I positive adult Tcell leukemia/lymphoma (ATLL) in Chile. Leukemia 1994; 8: 1763-7.

26. Osame M, Matsumoto M, Usuku K, Izumo S, Ijchi N, Amitani $\mathrm{H}$ et aL. Chronic progressive myelopathy associated with elevated antibodies to human TLymphotropic virus type I and adult T-cell leukemia like cells. Ann Neurol 1987; 21: 117-22.

27. Cartier L, Ramírez E. Presence of HTLV-I Tax protein in cerebrospinal fluid from HAM/TSP patients. Arch Virology 2005; 150: 743-53.

28. Haller K, Wu Y, Derow E, Schmitt I, Jeang KT, GrassmanN R. Physical interaction of human T-cell leukemia virus type I tax with cyclin- dependent kinase 4 stimulates the phosphorylation of retinoblastoma protein. Molecular Cell Biol 2002; 22: 3327-38.

29. ReDdy TR, Li X, Jones Y, EuLSman MH, Ching GY, Lem RR, Wong-Staal F. Specific interaction of HTLV tax protein and a human type IV neuronal intermediate filament protein. Medical Sciences 1998; 95: 702-7.

30. Chiari E, Lamsoul I, Lodewick J, Chopin C, Bex F, Pique C. Stable ubiquitination of Human T-cell leukemia virus type 1 Tax is required for proteasome biding. J Virology 2004; 78: 11823-32. 